\title{
MIÍASE HUMANA: CASO CLÍNICA
}

\section{ARTIGO ORIGINAL}

SILVA, Agnaldo Plácido da ${ }^{1}$, PLÁCIDO, Eloá Jessica Mendes dos Santos², MORAES, Walber Breno de Souza ${ }^{3}$

SILVA, Agnaldo Plácido da. PLÁCIDO, Eloá Jessica Mendes dos Santos. MORAES, Walber Breno de Souza. Miíase humana: Caso clínica. Revista Científica Multidisciplinar Núcleo do Conhecimento. Ano 05, Ed. 08, Vol. 10, pp. 39-46. Agosto de 2020.

ISSN: 2448-0959,

Link de acesso: https://www.nucleodoconhecimento.com.br/saude/miiase-humana, DOI: 10.32749/nucleodoconhecimento.com.br/saude/miiase-humana-caso-clinica

\section{RESUMO}

A Miíase é considerada uma infestação dermatozoonose causada por infestação de larvas de dípteros em tecidos ou órgãos, que depositam os seus ovos em humanos ou em animais, que durante certo período, se alimentam dos tecidos vivos ou mortos do hospedeiro a ocorrência de miíase na cavidade bucal pode se considerado uma coisa rara. Esse tipo de enfermidade acomete na maioria das vezes pessoas de nível socioeconômico baixo, imunocomprometidas, idosos acamados e com desordens psiquiátricas. Devido ao seu grande potencial destrutivo, uma prevenção e tratamento apropriado em tempo hábil e de grande importância, também se observa pouco conhecimento do profissional de odontologia para o diagnóstico e tratamento de tal patologia, Por este motivo, o presente trabalho relata um caso clinico de miíase oral em um idoso acamando com histórico de lesão neoplasia maligna de laringe/glote, apresentando debilidade física e mental e higiene corporal

\footnotetext{
${ }^{1}$ Doutorando em Ciências Biomédicas pela IUNIR- Instituto Universitário Italiano de Rosário - Argentina. Especialista em Cirurgia e Traumatologia Bucomaxilofacial pela Ciodonto - Clínica Integrada de Odontologia. Graduado em odontologia pela ASCES - Associação Caruaruense de Ensino Superior. Graduado em Biólogo pela UPE - Universidade de Pernambuco.

${ }^{2}$ Graduanda do Curso de Fisioterapia da Faculdade UNINASSAU.

${ }^{3}$ Licenciatura em Biologia UPE- Universidade de Pernambuco. Mestre em Recursos Naturais - UFCG. Professor na UNOPAR.
} 
inadequada e falta de selamento labial que levou à infestação de larvas na língua. O diagnóstico foi estabelecido clinicamente com base na observação de sangramento na língua, descolamento dos tecidos e presença de larvas que estavam entre o segundo e terceiro estágio de desenvolvimento. $\mathrm{O}$ tratamento foi iniciado como a hospitalização do paciente para debridamento dos tecidos necróticos e remoção das larvas e prescrição de ivermectina. Pacientes acamado e com debilidade física e metal constituem um grupo de risco para miíase bucal, sendo de grande importância a necessário de orientar cuidadores e familiares em relação aos cuidados odontológicos com a finalidade de prevenção desta patologia. Contudo, a falta de um consenso sobre a melhor conduta terapêutica para os casos de míase oral, foi tomado como conduta terapêutica para a enfermidade a remoção mecânica das larvas e instituição do uso oral da ivermectina.

Palavras-chave: Larva, míase humana, moscas, saúde pública.

\section{INTRODUÇÃO}

Miíase é definida como uma patologia em que há pestilência de larvas de moscas que se alimentam de tecidos vivos ou mortos (VINIT; JAYAVELU e SHRUTHA, 2013), apesar dessa parasitose ter sido descrita durante muitos anos por pesquisadores, o termo técnico para designar a bicheira foi sugerido em 1840 pelo reverendo F. W. Hope em seu trabalho "On insects and their larvae occasionally found in the human body", onde é proposto o uso do termo "miíase", que é derivada das palavras gregas myia (mosca) e ase (doença) (GUIMARAES; PAPAVERO e PRADO, 1983). Na literatura hindu a mí́ase foi considerada, pela mitologia como punição dos pecadores (PARMAR; DAVESSAR et al., 2018).

Os pacientes com Miíase, em geral apresentam alguns fatores que levam à predisposição para o seu desenvolvimento, tais como retardo mental, distúrbios psiquiátricos, senilidade, doenças vasculares, neoplasias, diabetes e imunodepressão e etilismo crônico, e ocorre preferencialmente em idosos. (MARQUEZ; MATTOS e NASCIMENTO, 2007) (SILVEIRA; PINHEIRO et al., 2015) 
Porém, os fatores de maior relevância para o surgimento da Míase ainda é a ocorrência de lesões expostas com exsudações e higiene corporal e oral deficientes (NASCIMENTO; OLIVEIRA et al., 2005) (TOURÉ, 1994).

Esta é uma situação de severidade fatal para o paciente, além de causar dor e destruição de tecidos. A Miíase oral pode se apresentar como laceração da cavidade oral, inchaço da mucosa oral, inflamação na gengival (RIBEIRO; PEREIRA et al., 2001). "No caso de Miíase cavitaria, que compreende as regiões da boca e nariz e seios paranasais, pode-se afirmar que é um tipo de míase bastante raro" (BARNABÉ; FERRAZ et al., 2016). A variedade mais prevalente de espécies de moscas responsável pela maioria dos casos de mí́ases inclui Cochliomyia hominivorax, Chrysomya bezziana, Oestrus ovis, Wohlfahrtia magnifica e a Musca doméstica. A incidência de infecção é rara mesmo em países em desenvolvimento (KHAN; SABIR et al., 2018) (TOURÉ, 1994).

O tratamento para miíase consiste basicamente na remoção manual das larvas, com - auxílio da cureta e pinça clínica, geralmente sob anestesia ou analgesia, dependendo do estado clínico do paciente, a remoção das larvas tem que ser feita de modo cuidadoso, para que as larvas não sejam fragmentadas, e os seus restos permaneçam no local, gerando um processo infeccioso (CAVALCANTI, 2008), embora exista no mercado alguns produtos que possa ser utilizados para facilitar a remoção (BARNABÉ; FERRAZ et al., 2016), a literatura relata com bastante sucesso, a utilização sistêmica de uma dose de ivermectina, um antibiótico macrolídeo semissintético para o tratamento de casos mais severos envolvendo a existência de Miíase oral, demonstrando ser um método seguro nas dosagens recomendadas de $200 \mu \mathrm{g} / \mathrm{kg}$. Mesmo nas dosagens de 300 ou $400 \mu \mathrm{g} / \mathrm{kg}$, pacientes submetidos ao tratamento não apresentaram qualquer efeito colateral clínico importante, a não ser leve prurido (GEALH; FERREIRA et al., 2009) (RIBEIRO; PEREIRA et al., 2001).

Podemos classifica a Miíase em três diferentes tipos: biontófagas ou primárias que são aquelas larvas de dípteros que desenvolvessem sobre ou dentro de 
vertebrados, alimentando-se dos tecidos do hospedeiro vivos. Dentre essas espécies, podemos encontra Cochliomy homini vorax e Dermatobia hominis. Necrobiontófogas secundárias são aqueles na qual as larvas de dípteros se desenvolvem em matéria orgânica que já se encontra em decomposição (cadáveres), atuando como saprófagas, mas também podem acometer os tecidos necrosados em um hospedeiro vivo. Os gêneros mais comuns são: Lucília, Phaenicia, Musca e Fannia. Pseudomíase (acidental): essa pode ocorre por ingestão de ovo e/ou larvas de dípteros presentes em alimentos contaminados ingerido pelo hospedeiro, ocasionando um distúrbios intestinais (CAVALCANTI, 2008) (BOROS; BOROS et al., 2006).

\section{CASO CLÍNICO}

Paciente do sexo masculino com 69 anos de idade, diagnosticado com neoplasia maligna na língua (em tratamento quimioterápico) deu entrada na emergência do Hospital Regional Dom Moura em Garanhuns - Pernambuco com queixa de dores e incomodo na região da boca a varias semana, foi encaminhada ao serviço de Cirurgia e Traumatologia Bucomaxilofacial. Na admissão, o paciente estava afebril, orientado e cooperativo, observou-se sangramento na boca, considerando relato da família que a paciente tinha problemas dentários, foi realiza exames. $\mathrm{Na}$ avaliação intra-oral mostrou uma lesão ulcerativa bem definida com tecido necrótico central e várias larvas vivas na língua. (Figura 1) 
Figura 1 - Larvas na língua.

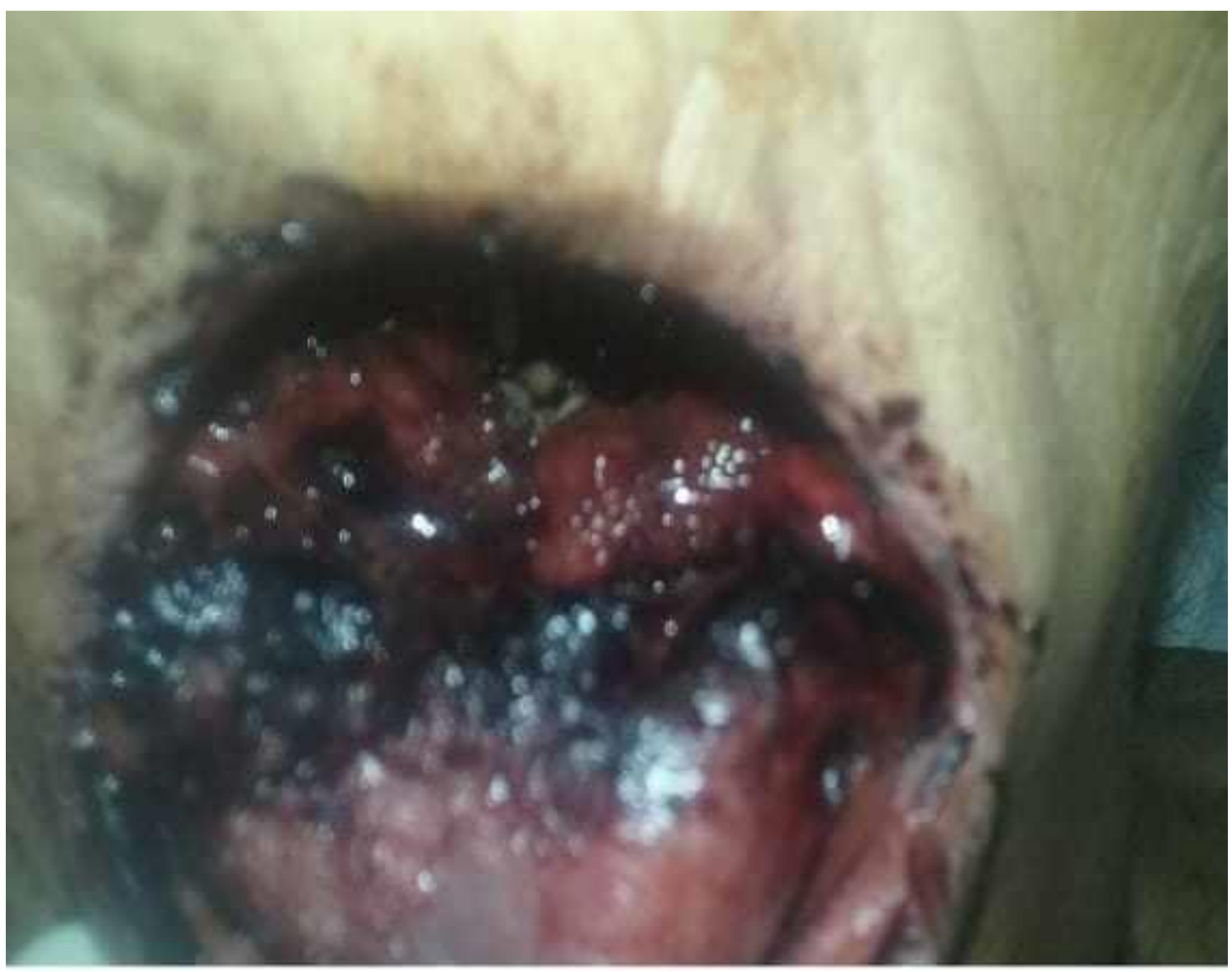

Fonte: Os autores (2020).

O paciente acometido pela enfermidade apresentava fatores predisponente tais como debilidade física e mental, desidratação, higiene corporal inadequada, diabetes, desnutrição, respiração bucal durante o sono e uma manutenção da higiene bucal precária.

Assim, o tratamento sintomático primário foi realizado. A ferida foi limpa e desinfetada com solução de Clorexidina $0,12 \%$. As larvas foram removidas manualmente sobre anestesia local com a ajuda de pinça clínica, o campo todo asséptico, as larvas neste caso foram coletadas e colocadas numa bandeja clínica. Foram retiradas aproximadamente 80 larvas da região, sendo que não se conseguiu retirar todas, (Figura 2). 
Figura 2 - Larvas removidas da lesão

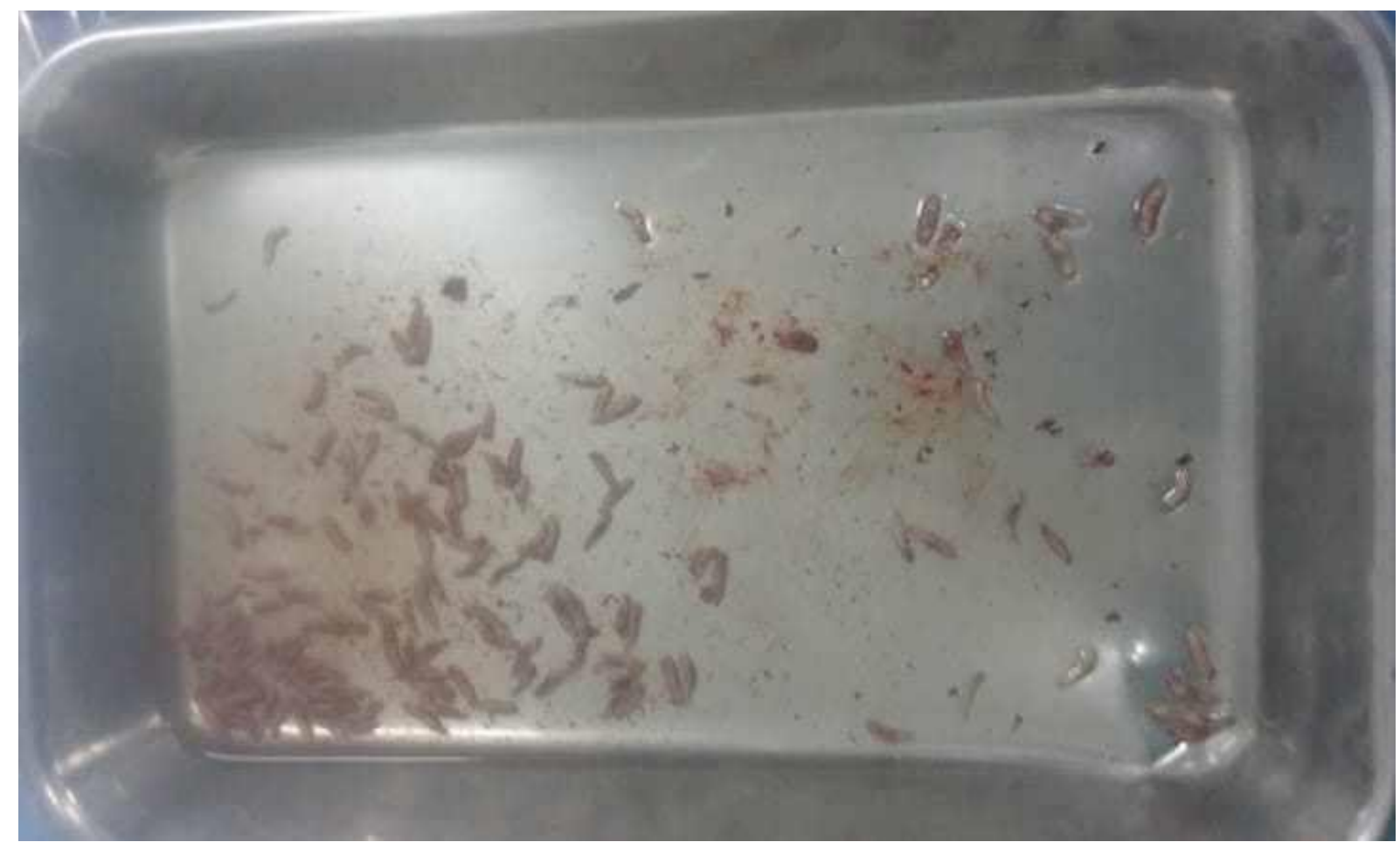

Fonte: Os autores (2020).

O paciente ficou internado e antibioticoterapia endovenosa foi iniciada Cefalotina $1 \mathrm{~g}$, Dipirona e Cetoprofeno, e uma dose oral única de Ivermectina dois comprimidos, ou seja, 12 mg (aproximadamente $200 \mu \mathrm{g} / \mathrm{kg}$ ), Após 10 dias haviam sido erradicada todas as larvas restantes, não havendo necessidade de complementação da Ivermectina.

\section{DISCUSSÃO}

Durante o processo de desenvolvimento das larvas, os tecidos adjacentes apresentam processo inflamatório, com ou sem ulceração ou necrose dos tecidos (CARVALHO; SANTOS et al., 2008). Muitas complicações sérias podem ocorrer devido à miíase: celulite, erosão de ossos e dentes, bacteremia e morte (SZAKACS e MACPHERSON, 2007). 
Em muitos os artigos consultados observamos que os autores citam que a míase bucal é uma patologia rara, e que os dípteros não têm preferência por idade, sexo e etnia. E que a infestação da larva de dípteros é mais na zona rural, infestando animais domésticos como cachorro, gatos, porcos, boi. A opinião geral dos autores é que as pessoas que foram infestadas pelas larvas são, deficientes mentais, pessoas de pouca higiene corporal e bucal, como pouco grau de instrução, pessoas de baixo grau socioeconômico (BOROS; BOROS et al., 2006).

O diagnóstico de miíase humana é clínico, mais para que se possa detectar alguma de suas complicações pode ser necessária à realização de tomografia computadorizada, ultrassonografia ou ressonância nuclear magnética (SHENOUDA; ENTEN et al., 2018).

A presença de larvas na pele desencadeia uma resposta inflamatória local com a migração e proliferação de células inflamatórias, como neutrófilos, mastócitos, eosinófilos, fibroblastos e células endoteliais. No entanto, a contagem completa de células sanguíneas pode mostrar níveis elevados de leucócitos e eosinófilos (PAYNE e COSGROVE, 1966) (SHENOUDA; ENTEN et al., 2018).

Alguns autores defendem um tratamento convencional da Miíase, que inclui a remoção das larvas com ajuda de substâncias químicas, que tem como finalidade promove a asfixia das larvas induzindo a sua saída da lesão. Já em lesões maiores onde apresenta uma quadro clinico de celulite adjacente seria indicada um debridamento dos tecidos locais com a retirada de tecidos necrosados, porem outros defendem como ideal, o tratamento cirúrgico, que possibilita a remoção de todas as larvas aliada a uma debridação, e antibióticos para preveni infecção secundarias, outro método ja foram tentado como o uso de dose única de ivermectina (PARMAR; DAVESSAR et al., 2018).

A Miíase pode se vista como um problema de saúde publica que pode ser prevenida eliminando os fatores de risco para a saúde humana, como a falta de saneamento básico e disposição inadequada de lixo, onde fica exposto material orgânico, que 
atrai insetos e pequenos animais, criando um ciclo sustentável de sujeira. $\mathrm{O}$ saneamento precário é provavelmente o fator de risco mais importante para miíase humana (FRANCESCONI e LUPI, 2012 ).

\section{CONCLUSÃO}

$\mathrm{Na}$ literatura já foram propostos vários tratamentos para miíase cavitária que variam desde a extração mecânica até o uso de substâncias tópicas, orais e endovenosas. Porem um diagnostico precoce e correto possibilita um tratamento com um prognóstico favorável. Todavia, qualquer que seja o meio empregado, é indispensável que o paciente seja orientado quanto à adoção de medidas adequadas de higiene pessoal. Contudo, não existe um consenso sobre a melhor conduta terapêutica para os casos de miíase oral.

\section{REFERENCIAS}

BARNABÉ, A. S. et al. Epidemiologia Da Miíase Cutânea: Revisão Da Literatura. Atas de Ciências da Saúde, São Paulo, v. 4, n. 2, p. 14-22, Abril - Junho 2016.

BOROS, L. F. et al. Miíase Labial. Revista Dens, v. 14, n. 1, p. 1-10, Revista Dens, v.14, n.1, maio/outubro 20062006.

CARVALHO, R. W. F. et al. Oral and maxillofacial myiasis associated with epidermoid carcinoma: a case report. Journal of Oral Science, v. 50, n. 1, p. 103-105, 2008.

CAVALCANTI, A. L. Miíase Oral: etiologia, diagnóstico e tratamento. Rev. Fac. Odontol. Porto Alegre, Porto Alegre, v. 49, n. 2, p. 32-35, maio/ago. 2008.

CAVALCANTI, A. L. Miíase Oral: etiologia, diagnóstico e tratamento. Rev. Fac. Odontol. Porto Alegre, Porto Alegre, v. 46, n. 2, p. 32-35, maio/ago. 2008.

FRANCESCONI, ; LUPI,. Myiasis. Clinical Microbiology Reviews , v. 25, n. 1, p. 79 105, Jan. 2012. 
GEALH, W. C. et al. Treatment of oral myiasis caused by Cochliomyia hominivorax: two cases treated with ivermectin. British journal of Oral and Maxillofacial Surgeons, v. 47 , n. 1, p. 23-26, January 2009.

GUIMARAES, J. H.; PAPAVERO, ; PRADO, A. P. D. As Mi1ases Na Região Neotropical. Revista Brasileira De Zoologia (Identificação, Biologia, Bibliografia), São Paulo, v. 1, n. 4, p. 239.416, 1983.

KHAN, B. A. et al. Oral and cutaneous myiasis in a 5 year old child from Karachi, Pakistan. Le Infezioni in Medicina, v. 4, p. 385-388, 2018.

MARQUEZ, A. T.; MATTOS, M. D. S.; NASCIMENTO, S. B. Miíases associadas com alguns fatores sócio-econômicos em cinco áreas urbanas do Estado do Rio de Janeiro. Revista da Sociedade Brasileira de Medicina Tropical, v. 40, n. 2, p. 175180, março - abril 2007.

NASCIMENTO, E. M. F. D. et al. Miíases Humanas Por Cochliomyia Hominivorax (Coquerel, 1858) (Diptera, Calliphoridae) Em Hospitais Públicos Na Cidade Do Recife, Pernambuco, Brasil. Entomología y Vectores, v. 12, n. 1, p. 37-51, 2005.

PARMAR, S. et al. Tracheostomal Myiasis: A Case Report And Review Of Literature. International Journal of Scientific Research, v. 7, n. 12, p. 4-6, December 2018.

PAYNE, J. A.; COSGROVE, G. E. Tissue changes following Cuterebra infestation in rodents. The American Midland Naturalist, v. 75, n. 1, p. 205-213, Jan. 1966.

RIBEIRO, F. A. Q. et al. Tratamento da miíase humana cavitária com ivermectina oral. Rev Bras Otorrinolaringol, v. 67, n. 6, p. 755-761, nov./dez. 2001.

SHENOUDA, M. et al. Human Botfly: A Case Report and Overview of Differential Diagnosis. J Investig Med High Impact Case Rep., v. 6, Jan-Dec; 2018.

SILVEIRA, M. A. A. et al. Cavitary myiasis mimicking peritonsilar abscess. Brazilian Journal of Otorhinolaryngology, v. 81, p. 336-338, 2015. 
SZAKACS, T. A.; MACPHERSON,. Nosocomial myiasis in a Canadian intensive care unit. CMAJ, v. 177, n. 7, p. 719-720, 25 September 2007.

TOURÉ, S. M. Les myiases d'importance économique. Rev. sci. tech. Off. int. Epiz., 1994, 13 (4), 1053-1073, v. 13, n. 4, p. 1053-1073, 1994.

VINIT, G. B. ; JAYAVELU, P.; SHRUTHA, S. P. Oral myiasis in a maxillofacial trauma patient. J Pharm Bioallied Sci., v. 5, n. 6, p. 195-197, 5 Jul 2013.

Enviado: Fevereiro, 2020.

Aprovado: Agosto, 2020. 